\title{
Trends in the British wine market and consumer confusion
}

\author{
Leonardo Casini \\ University of Florence, Florence, Italy \\ Alessio Cavicchi \\ University of Macerata, Macerata, Italy, and \\ Armando Maria Corsi \\ University of Florence, Florence, Italy
}

\begin{abstract}
Purpose - The purpose of this paper is twofold: to give a descriptive outlook of the competitive environment in the UK wine market, and then to show the presence of "consumer confusion" elements in it.

Design/methodology/approach - The consumer confusion concept has been considered as a framework in order to test the existence of the principal elements of consumer misunderstanding in the buying process. Data have been collected from secondary sources and through in-depth semi-structured interviews among a sample of 40 stakeholders of the wine supply chain in the UK.

Findings - The main findings prove the existence of the essential characteristics that can generate a certain degree of consumer confusion, and the relative consciousness of key informants that some strategies need to be adopted to reduce it, although only a few have already been performed.

Originality/value - This paper is probably the first work that tests the consumer confusion conditions through a qualitative analysis following the expectations of previous research conducted by Drummond and Rule.
\end{abstract}

Keywords Wines, Consumer behaviour, Depth interviews, Supply chain management, Marketing mix, United Kingdom

Paper type Research paper

\section{Introduction}

The British wine market is nowadays dominated by a decreasing number of expanding multinationals (Jackson et al., 2000): the main reason of this decline is the difficulty faced by many exporters of supplying sufficient quantities of wine in order to ensure year-round availability to customers (Stening et al., 2004). The forecasts of Anderson et al. (2003) that by 2005 New World (NW) wine producing countries would surpass Old World (OW) countries have been fully realized. In 2003, for the first time, Britons drank more NW wines than traditional European vintages (Euromonitor International, 2006). A massive effort in marketing and export strategies has brought Australia into place as the current market leader (WARC, 2005). Thus, the British wine market is completely differentiated: every international group owns many labels and there is still room for more varied productions. Moreover private labels (PLs) play a crucial role, as supermarkets continue to buy grapes and hire winemakers to produce wine under their own labels (Stening et al., 2004). Therefore, UK is a market extremely competitive and the proliferation of labels together with an overloading of information leads to an increasing consumer's confusion.

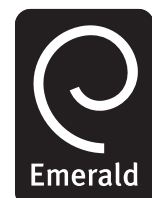


$\mathrm{BFJ}$

110,6

546
The purpose of this work is first, to give a descriptive outlook of the competitive environment in the UK wine market and then to verify the main factors of "consumer confusion" framework developed by Mitchell and Papavassiliou (1999) and applied to the UK wine industry by Drummond and Rule (2005).

Thus, after an introductive outline of recent trends under a marketing-mix perspective, a theoretical framework is given, in order to illustrate and discuss the main features of the consumer confusion concept. Subsequently, materials and methods used to collect primary and secondary data are illustrated. Then, the results of a qualitative research conducted among a convenient sample of 40 stakeholders of the wine supply chain in the UK are presented. Finally, some discussions about the risk that the development of this market can generate on consumers' confusion and buying behaviour are provided.

\section{Recent trends under a marketing mix perspective}

In order to understand the dynamism of the competitive environment, it is necessary to outline the recent trends of the wine market in the United Kingdom according to the "4Ps" of the marketing mix.

\section{Product}

The forecasts of Anderson et al. (2003) that by 2005 NW wine producing countries would surpass OW countries have been fully realized, with Australia being the current market leader (WARC, 2005). The growth of the British wine market benefited from booming sales in sparkling wine, and the popularity of still rosé wine showed no sign of slowing down. The volume sales of red wines outstripped the value sales. The value of the market for white wines demonstrated the biggest rate of increase between 2000 and 2005, with Merlot, Cabernet Sauvignon and Shiraz being the top three red varieties sold, and Chardonnay, Sauvignon Blanc and Pinot Grigio the preferred white varieties in 2005 (Euromonitor International, 2006).

Nevertheless, competition is going to increase because some opportunities for national production related to environmental events are occurring: climate conditions have not been so good in Britain since the medieval warm period. The geology of southern England appears to be particularly favourable to viticulture (Selley, 2004). Richardson and Dennis (2003) showed how UK wine firms may develop their marketing strategies and they appear quite optimistic in forecasting an increasing success for British wine. Moreover, if British production will increase during next years is arguable a trend in domestic wine consumption similar to those evidenced in some States of US, where many local people are taking pride in buying a local product. In fact, as pointed out by Read (2004) as local wine quality improves, current wine consumers are likely to buy more domestic wines, thus potentially reducing the proportion of their wine purchases from European sources or other imports.

\section{Prices}

In terms of prices a general upward movement can be observed. Red wine increased in the £5-6 price range per bottle, although more than 50 per cent of the total sales are registered on the $<£ 5$ fascia (Euromonitor International, 2006). Price of white wines increased too, but they sell at lower price points compared to red, as 58 per cent of white wines are sold under $£ 5$ (Steiner, 2004; Euromonitor International, 2006). The 
new image of still rosé wine shrugged off its cheap image and it can now command higher prices. The majority of rosé (29 per cent) is sold between $£ 5$ and $£ 6$. On the contrary, due to massive promotional activities, the average price of champagne and other sparkling wines declined by $£ 1.3$ at current prices by 2000 and 2005 .
Trends in the British wine market

\section{Promotion}

The promotion of alcoholic drinks in the UK faces the issue of binge drinking (Engineer et al., 2003; Prime Minister's Strategy Unit, 2004). Social costs of alcoholism have made public and private bodies set up a series of rules and laws in order to prevent alcohol abuse. These at least partially contributed to the decline in advertising expenditures over the period 2000-2004. However, this could also be the consequence of suppliers choosing to devote more of their financial resources to price promotional activities, because of the rewards of product visibility in-store. In terms of promotions, "price cuts" continue to control the sales of wine in the UK, while discounted cases and multibuys, although present, do not have the same level of appeal as the former (Euromonitor International, 2006). Price cuts started to acquire popularity in the run-up to the Millennium celebrations as the retail trade aimed to benefit from the expected rush in consumer demand. At that stage, as the wine boom in UK was at the dawn, deep discounts were relatively unusual. Since then it has become more commonly used as the major supermarkets have sought to consolidate their share of consumer spending, market sector by market sector. Most of the discounting is not at the instigation of producers, but rather by retailers at the expense of their margins. Major brands generally prefer promotional discount campaigns, while smaller producers tend to devote more attention to other aspects of the marketing mix, sharing resources with each other, such as bottling and warehousing. The Press is the favourite channel for advertising, despite a decrease in the importance of this medium in the last few years. In the mean time, television is gaining an increasingly important role, while radio, cinema and outdoor events have decreased in importance (Mintel International, 2005).

\section{Placement}

Grocery chains largely control the sales of wine throughout the country. The introduction of supermarkets to the wine retail market deeply reshaped the British wine sector, giving birth to the explosion of the wine market during the 1980s and the 1990s. Moreover, new drunk driving laws, the popularisation of wine, the availability of high quality, inexpensive wine from NW wine producing countries, and the economic recession (Stening et al., 2004) brought the off-trade sector to account for 79 per cent of all wine sold in the UK (Euromonitor International, 2006). Within this context, supermarkets wine sales grew from 55 per cent in 1990 to 69 per cent in 2005.

The importance of the off-licence sector, has been highlighted by Steiner (2004). He argued that the interest in the British wine and off-licence sector lies in the fact that:

- British wine experts are renowned for their ability in selecting, importing, bottling and cellaring wines.

- British consumers have traditionally been exposed to a large variety of wines coming from all over the world, as England has never produced much wine of its own. 
$\mathrm{BFJ}$

110,6

\section{8}

Specialists have decreased over the last 30 years (Byrom et al., 2002), but something could change in the future as more and more people become interested in wine.

The competition among grocery multiple retailers

Supermarkets account for the 69 per cent of all the wine sold in the UK (Euromonitor International, 2006). According to Mintel International (2005) Tesco and Asda are those, among other supermarkets, to have registered the best performances in wine sales in the review period. The former consolidated its market leadership and also became the current online retailer, while the latter continues to show the positive effects of the brand's acquisition by Wal-Mart. The "parent company" reinstated the Every-Day-Low-Prices (EDLP) strategy, which has been always part of the "DNA" of Asda. This strategy is part of a general theme of growth, which is also reflected in the attention it devotes to PLs and in the increasing expansion towards larger and better retail stores. On the contrary, Tesco, together with Sainsbury's, is expanding towards convenience store formats, seeking to dominate this growing market (Hackney et al., 2006). Sainsbury's follows as second in ranking, thanks to its area coverage and a strategic focus on high quality products, PLs included. Safeway does no longer exist, as it is now part of the WM Morrisons Supermarkets. Hence, due to this acquisition, Morrisons became an important national player in the British arena (Hackney et al., 2006). Somerfield remained almost stable in the review period, showing a trend towards convenience stores' retail formats. Waitrose registered gradual but steady growth in market share Marks \& Spencer (M\&S) also plays an important role because it only sells its own labels. However, despite the limitations of selling exclusively PLs, M\&S has always tried to build its reputation on quality, dependability and good value. It has tailored its marketing efforts towards consumers with higher incomes (Steiner, 2004), demonstrating the potentialities of PLs, if properly marketed. Therefore, in the last few years many retailers underwent a deep reorganization of store formats and the entire logistics chain (Mintel International, 2005).

\section{The consumer confusion concept}

The value of information in the buying process has been widely discussed in wine marketing literature (Lockshin, 2003). It has been demonstrated that even if consumers search for a great deal of information before buying, their decision is usually based on a small number of cues (Lockshin et al., 2000) and that while highly involved consumers utilise more information, low involvement consumers try to simplify their choices using risk reduction strategies. Consequently Spawton (1991) suggests that excepting a few experts at the high end of the market, most wine purchasers are highly risk-sensitive and their purchases are ruled by risk-reduction strategies. Risks can be functional (the taste of wine), social (the embarrassment subsequent to a wrong decision), financial (the cost especially if the wine is expensive) or physical. Thus, consumers are concerned with an enormous amount of information like varietals, brand labels, grocery retailers indications, recommendations which impacts on perceived risks. Redundant and ambiguous information might lead to a lack of trust in wine retailers and producers. Therefore, the right level of available information in wine 
market has to be provided with regard to the kind of consumer knowledge and attitudes.

The concept of consumer confusion (Mitchell and Papavassiliou, 1999; Mitchell and Walsh, 2005) has been taken into consideration by Drummond and Rule (2005), in order to analyse the current situation of the UK wine market. The authors cited the definition of consumer confusion given by Walsh (1999) as an uncomfortable state of mind that primarily arises in the pre-purchase phase and which negatively affects consumers' information processing and decision-making abilities and can lead to consumers making suboptimal choices. They stated, according to Mitchell and Papavassiliou (1999), that the causes of confusion in wine market may be attributed to:

- available access to increasing amounts of information;

- unprecedented levels of product proliferation;

- increasing use of imitation strategies;

- consumers shopping in new/unfamiliar environments.

By means of semi-structured interviews with 40 key informants belonging to the wine supply chain, including producers, distributors, agents and other stakeholders, this research aims to verify the reasons and the possible effects of consumer confusion.

\section{Research method}

Materials and methods

The key informant technique is an expert source of information (Marshall, 1996). This technique is well described by Tremblay (1955), who defines it as a technique "pre-eminently suited to the kinds of qualitative and descriptive data that are difficult or time consuming to unearth through structured data-gathering techniques, such as questionnaire surveys". The main advantage is that this technique provides data of good quality in a relatively short period of time and requires a small sample of respondents (only those who are considered "experts") chosen through the matching of their characteristics to specifically selected parameters. The disadvantages are that informants may not represent the view of the majority of the population (Marshall, 1996). The identification of informants may also be incorrect because some companies tend to propose individuals who do not have the necessary skills of a true key informant (Willaims, 1967). Informants are different from informers, as the latter may be more easily influenced (Lincoln and Guba, 1985).

The steps needed to implement the technique may be summarized as follows:

(1) Preliminary selection of informants. Informants, who belong to all the phases of the supply chain (producers, importers, distributors, etc.) are chosen.

(2) Deviation from preliminary design. As soon as it was seen that there was an overlap of roles, it was necessary to add or confirm those key informants who fulfilled the selected criteria, and delete those who did not. Moreover, in the course of contacting and interviewing them, some informants made suggestions to the interviewers of other contacts who were particularly well qualified to give information.

(3) Design of the questionnaire. In order to test marketing mix tools as sources of consumer confusion[1], it was decided to build an open ended questionnaire of seven questions, each supported by one or more probing questions. The
Trends in the British wine market

549 
$\mathrm{BFJ}$

110,6

\section{0}

Agent

Alcoholic drink company

Distribution company Importer

\section{Table I.}

Producer

A definition of the role of the professional figures interviewed technique of face-to-face in-depth interviews was adopted. The interviews lasted from 15 to $25 \mathrm{~min}$. The order of the questions tried to minimize problems of order bias. The name of the respondent was first noted, the society which he/she works for, the role held in it, and the years on duty. Then, an opinion was requested about the current situation and the prospects for the wine market in the UK, with a particular focus on relationships among wine and substitute products and point of sales for wine. Subsequently, the interviewee was asked about the current situation and the prospective for private labels in British supermarkets. A fourth question regarded the strategy adopted by wineries (placement, logistics, distribution, etc.) to face the British wine market. A question was then asked as to what the respondent considers the strengths of products kept on supermarket shelves are in relation to consumers' needs, trying also to elicit some information on the grape varieties used. The last two questions referred to the strategies adopted in terms of promotion and the price range of the wines supplied to the market.

(4) Interviews. The 40 selected key informants were contacted in advance, so as to confirm their availability in spending some time with the researchers. The interviews were completed between April and June 2006, during the "London International Wine and Spirits Fair" and were then analysed by the authors and partially transcribed. The sample included different professional figures: agents, alcoholic drink companies, distribution companies, importers and producers. A description of their role may be found in Table I.

The agents all came from the UK, although with different focuses on NW or OW wine producing countries. Then, it was possible to interview members of ten different alcoholic drinks companies. Three of them have their headquarters in France, and two in the USA, while one each comes from Australia, Spain and the United Kingdom. The

$\begin{array}{ll}\text { Agent } & \text { An agent is someone who acts on behalf of a wine firm to a retailer. In } \\ \text { fact, any firm has the power to control a foreign market completely, } \\ \text { unless it has someone physically present there. An agent has to first } \\ \text { understand the market and have a keen sense for bargain wines, in } \\ \text { order to position the correctly (Gold, 2006) } \\ \text { An alcoholic drinks company owns brands and/or wine firms (or has } \\ \text { long-term contracts with them) in one or more countries around the } \\ \text { world } \\ \text { Alcoholic drink company } \\ \text { An istribution company physically distributes wine in a country } \\ \text { An importer can be defined as someone who imports wine from the } \\ \text { country of origin to the country of destination. He deals with clearing } \\ \text { the wine through customs and takes ownership of the wine delivered } \\ \text { to the customs warehouses. He supplies and invoices the HoReCa } \\ \text { sector or independent wine shops directly from his warehouses. The } \\ \text { importer is the final contributor to the price of the wine, adding on a } \\ \text { percentage before selling it (Gold, 2006) } \\ \text { A producer can be defined as someone who makes wine in just one } \\ \text { country, taking care of the entire productive process until the moment } \\ \text { in which the wine is bottled and/or packaged. Then, he needs to deal } \\ \text { with an agent, an importer, etc., through the other steps of the supply } \\ \text { chain }\end{array}$
fact, any firm has the power to control a foreign market completely, unless it has someone physically present there. An agent has to first understand the market and have a keen sense for bargain wines, in (or has world An importer can be defined as someone who imports wine from the country of origin to the country of destination. He deals with clearing to the customs warehouses. He supplies and invoices the HoReCa sector or independent wine shops directly from his warehouses. The importer is the final contributor to the price of the wine, adding on a country, taking care of the entire productive process until the moment in which the wine is bottled and/or packaged. Then, he needs to deal chain 
French company Pernod Ricard were interviewed twice, in order to see whether there were discrepancies between the European (Campo Viejo) brand's point of view and that of the Australian Jacob's Creek. All the three distributors interviewed came from the United Kingdom, as well as the nine importers. The research took also into consideration 12 producers coming either from NW or OW countries. The most representative regions were Italy and South Africa with four interviewees, followed by Australia with two members and by Argentina and France with one. The questionnaire also included a German third-party logistics provider and a member of the New Zealand Wine Growers, a professional body that "aims to represent, promote and research the national and international interests of the New Zealand wine industry" (New Zealand Wine, 2007). According to Bradley (1994) a third-party logistics provider is "a multiple logistics service located by a single vendor on a contractual basis". A detailed list of the respondents may be found in Table II.

\section{Results of the study}

Available access to increasing amount of information

This first reason of consumer confusion is mainly related to the complexity of product labels sometimes written with an unhelpful terminology and the aggressive promotions and price strategies applied by supermarkets.

Not only formats are similar between supermarkets - an interviewee said - We can find more or less the same grape varieties, the same brands, but maybe with different prices, or under different price promotion, or even with a slightly different packaging.

What is far more problematic, however, is the fact that beyond having a lot of information, customers face suggestions that are sometimes not coherent with one another. To offer an example, it has been noted that in more than one case, Italian wines are presented with some mistakes. For instance, Sicily is sometimes considered as separate from the rest of the country, whilst some promotions and labels present Sicily and Italy as the same region.

Clearly, supermarket chains try to reduce consumer confusion. For example, Tesco recently reviewed its wine range, and from August 2005 chose to expand the number of wines in the $£ 6-10$ bracket, while culling some in the $£ 4-5$ band, which looked too crowded: customers can apparently be overwhelmed by a huge range of similar wines at the same price. The aim is to make the category "easier to shop", and to encourage customers to try more unusual wines, which will be introduced under the Finest, store's own brand.

Another source of consumer confusion in the choice of wine in supermarkets, strictly linked with the price issue, is that of promotions. Generally, alcoholic drinks companies or importers organize in advance with the retailer the promotional activities of the year. A brand usually has two or three promotional periods per year.

The most common means of promotion is price cutting. The price of the wine is cut by $£ 1$ up to $£ 3.5$ according to the original price of the bottle. It means that retailers cut from a 10 per cent to a 50 per cent of the original price.

Multibuy, like "Buy one get one free" (BOGOF) is less used, although it has the same effect as selling a wine 50 per cent off.

\section{Trends in the British wine market}

551 


\section{$\mathrm{BFJ}$ 110,6}

552

\begin{tabular}{|c|c|c|}
\hline Interviewees & Role & Country of origin \\
\hline Adel & Agent & United Kingdom \\
\hline Agents 4 Wines & Agent & United Kingdom \\
\hline Albion Wine & Agent & United Kingdom \\
\hline Seckford Agents & Agent & United Kingdom \\
\hline Foster's & Alcoholic Drinks Company & Australia \\
\hline Boisset Wines and Spirits & Alcoholic Drinks Company & France \\
\hline Castel & Alcoholic Drinks Company & France \\
\hline J.P. Chenet & Alcoholic Drinks Company & France \\
\hline Pernod Ricard - Jacob’s Creek & Alcoholic Drinks Company & France/Australia \\
\hline Pernod Ricard - Campo Viejo & Alcoholic Drinks Company & France/Spain \\
\hline Freixenet & Alcoholic Drinks Company & Spain \\
\hline HWCG & Alcoholic Drinks Company & United Kingdom \\
\hline Brown Forman Wines & Alcoholic Drinks Company & USA \\
\hline Constellation Brands & Alcoholic Drinks Company & USA \\
\hline Brand Phoenix & Distributor & United Kingdom \\
\hline D\&D Wines International Ltd & Distributor & United Kingdom \\
\hline Freixenet (DWS) & Distributor & United Kingdom \\
\hline Alliance Wine & Importer & United Kingdom \\
\hline Buckingham Vinters International & Importer & United Kingdom \\
\hline Cellar Trends & Importer & United Kingdom \\
\hline $\mathrm{D} \& \mathrm{~F}$ & Importer & United Kingdom \\
\hline Enotria Wine Cellar & Importer & United Kingdom \\
\hline Great Western Wines & Importer & United Kingdom \\
\hline PLB & Importer & United Kingdom \\
\hline Stratford Wine Agencies & Importer & United Kingdom \\
\hline Wine Importers UK & Importer & United Kingdom \\
\hline Kuehne + Nagel Ltd & Logistics provider & Germany \\
\hline Diageo Argentinean Wines & Producer & Argentina \\
\hline Casella Wines & Producer & Australia \\
\hline De Bortoli Wines & Producer & Australia \\
\hline Maison Kuentz-Bas & Producer & France \\
\hline Cavalieri & Producer & Italy \\
\hline Michelotto Cantine & Producer & Italy \\
\hline Podere Vaglie & Producer & Italy \\
\hline Stefania Pepe - Organic Wines & Producer & Italy \\
\hline Boschendal & Producer & South Africa \\
\hline Distell & Producer & South Africa \\
\hline Golden Kaan & Producer & South Africa \\
\hline Wine Corp & Producer & South Africa \\
\hline New Zealand Wine Growers & Professional body & New Zealand \\
\hline
\end{tabular}

If you have to go to a party you prefer to go with just one bottle and pay 50 per cent off, because you believe it is of higher quality, rather then buying two bottles through a BOGOF, because you think they are of lower quality.

The third way of discounting wine is through a "Buy-two-get-third-free" promotion, as Thresher does all year round, but this is not as common as price cuts.

However, promotions tend to confuse customers, as they do not know what the real value of the wine they buy is. In order to reduce confusion an interviewee suggested the use of loyalty cards[2]. 
The product, instead of being cut off, gives more points than others in the loyalty card of the customer.

The company that organizes it explains that in this way, it is possible to exit the vicious circle of "wine sold only if it is on promotion". It said that customers are stimulated to buy wine, as it lets them gain more points on their loyalty cards, but the quality of the wine is less distorted than when using price cuts, BOGOF, etc. Another marketing manager, in fact, highlighted that retailers constantly deceive customers.

Consumers nowadays are used to buying wine on promotion, because they believe to have bought a higher quality wine at a lower price, but it is a pure psychological trick. Suppliers and retailers perfectly understand that; therefore, when they have to choose the final price of a label, they calculate a potential cut of $£ 1$ or $£ 2$.

This is the reason why statistics, newspapers, media, etc., show that the market is moving toward a "premiumisation" of the field. There is a common opinion among the managers interviewed: suppliers increase the original price of the bottle, bringing it from, for example, $£ 5.99$ to $£ 7.99$, but simultaneously increase the price cut of $£ 2$. In the end, the profit margin for the company is the same, but in the mind of consumers there is the conviction that they have found a good deal. The use of loyalty cards, on the contrary, will provide an incentive for purchasing wine at its original price, making the market less distorted.

\section{Unprecedented level of product proliferation}

If one observes the on-line wine range of the seven biggest supermarket chains, it is easy to verify the presence of 700 products from around the world, including red, white, rosé, sparkling and fortified varieties. Though the majority of products are presented in $75 \mathrm{cl}$ bottles, the range also includes several other formats including $25 \mathrm{cl}$ bottles and cans, and three-litre wine boxes.

Many interviewees agree on the fact that during last few years there has been a proliferation of wines on the shelves:

... wines are growing ... but now there are too many ...

... it is a very fragmented market, where there are many wine. It is important to stand out as much as you can ...

... the trend will continue ...

... English will find wines from the East of Europe. We will also find wines coming from non traditional wine areas, something that consumers never tasted ...

Nevertheless, the presence of a brand in the UK wine market is a necessity as confirmed by an international sales director:

The UK market is very difficult as there are five multiple supermarkets that sells the 80 per cent of the wine in the UK. If you are a producer, they put a lot of pressure on you and, if you want to be successful, you have to be quite inventive in marketing with these guys. Probably some other markets may be more interesting, but if you want to develop a brand you have to be in the UK market, you have to be seen in the UK market. It is a pure business decision.

On the other side customers themselves try to reduce their confusion. Several informants stated that if consumers have to choose between two wines that cost the same, then the
Trends in the British wine market

553 
$\mathrm{BFJ}$

110,6

554 power of brand is fundamental. If consumers still hesitate, it is vital to have a clear and simple label. As a brand manager of a distribution company underlined:

English consumers want brands and easy.

This means that they remember only few brands, but they want to clearly understand what they are drinking. They want to know whether the wine is a Cabernet, a Merlot, a combination of different grapes, etc. In this way they can associate this information with the sensations they had when they tried that label or that grape.

English consumers generally don't want to risk too much when they choose their wines and don't want to be betrayed by a wine they don't know very well.

\section{Increasing use of imitation strategies}

Within all the possible labels people may find in supermarkets, and beyond more traditional "copy-catting" strategies adopted by new brand to emulate successful existing ones (including the tendency to use traditional grape varieties of $\mathrm{OW}$ countries like Sangiovese or Barbera in NW areas), a particular attention has been devoted to private labels, as they represent an alternative but worthwhile way to trade wine in such a difficult sector. They may allow, in fact, selling a wine, which reminds of a successful product idea, a concept or a style (Drummond and Rule, 2005), at a price, which is generally lower than a branded product. Stening et al. (2004) recognised an important role to PLs; however, the comments on the current situation of PLs in the UK are controversial, showing a bias toward a pessimism regarding their future. "Private labels are dying" ... "Private labels are finished" ... "Private labels make a bad situation worse" ... "Brands are certainly the future", and "Brand is the key of the market" are some of the comments from this biased point of view.

The reason that limits their presence in the market is mainly that they do not have their own "life", but are linked to branded products. Another issue justifies this negative opinion about PLs:

They didn't evolve in these years.

The majority of the interviewees coming from NW countries underlined that retailers have never invested much effort in developing PLs in the wine industry. Though the experts cited thus far have a pessimistic attitude towards PLs, other respondents, the majority of whom coming from OW countries, seemed to have a very optimistic opinion about them, explaining that PLs may continue to have an important role if they are modified to meet the needs of the market. For this reason they should not appear any longer as an entry level, poor quality wine. This opinion is best summarized by this sentence:

PLs are really really good. They are a good way to try new wines, but it is retailer's responsibility to show what is inside these bottles.

\section{Consumer shopping in new/unfamiliar environments}

There are several ways in which wine can be delivered to consumers. As underlined by Drummond and Rule (2005) consumers are now more widely travelled and have access to online shopping and alternative distribution sources. This certainly increases the 
choice opportunities of consumers, but it can also complicate decision making, giving consumers a confusing range of choices.

According to the interviews, it is possible to summarize traditional and new tendencies of wine distribution in the UK, showing that there are some phases which are compulsory and common among all suppliers, while others (e.g. mail order and booze cruise) are expanding in recent years, as shown in Figure 1.

Thus, wine is traditionally delivered through an alcoholic drinks company or importer, with or without a warehouse and/or a sales/distribution team, dealing with a supermarket chain, specialist chain, or a chain in the HoReCa sector. Another solution wine firms may adopt is to have an agent or importer dealing with independent stores either in the on- or the off-trade. The third traditional way to enter the British wine market is to deal directly with independent stores either in the on- and the off-trade or with private firms.

However, nowadays new emerging methods are used:

(1) Personal import (booze cruise). This term refers to the practice of making a brief trip from Britain to France (or, more rarely, to Belgium) with the intent of buying alcohol or tobacco. The Office of National Statistics estimated that in the late 1990s and 2000 between 2-3 per cent (40-50 millions of litres) of the total amount of alcohol consumed in the UK, came in the country through cross-border shopping (Euromonitor International, 2006). This type of market is played by both UK and French actors. For instance, Tesco and Sainsbury's have their own branch in Calais, together with four French grocery multiple chains: Auchan, Casino, Carrefour and Leclerc. Furthermore, two UK-based

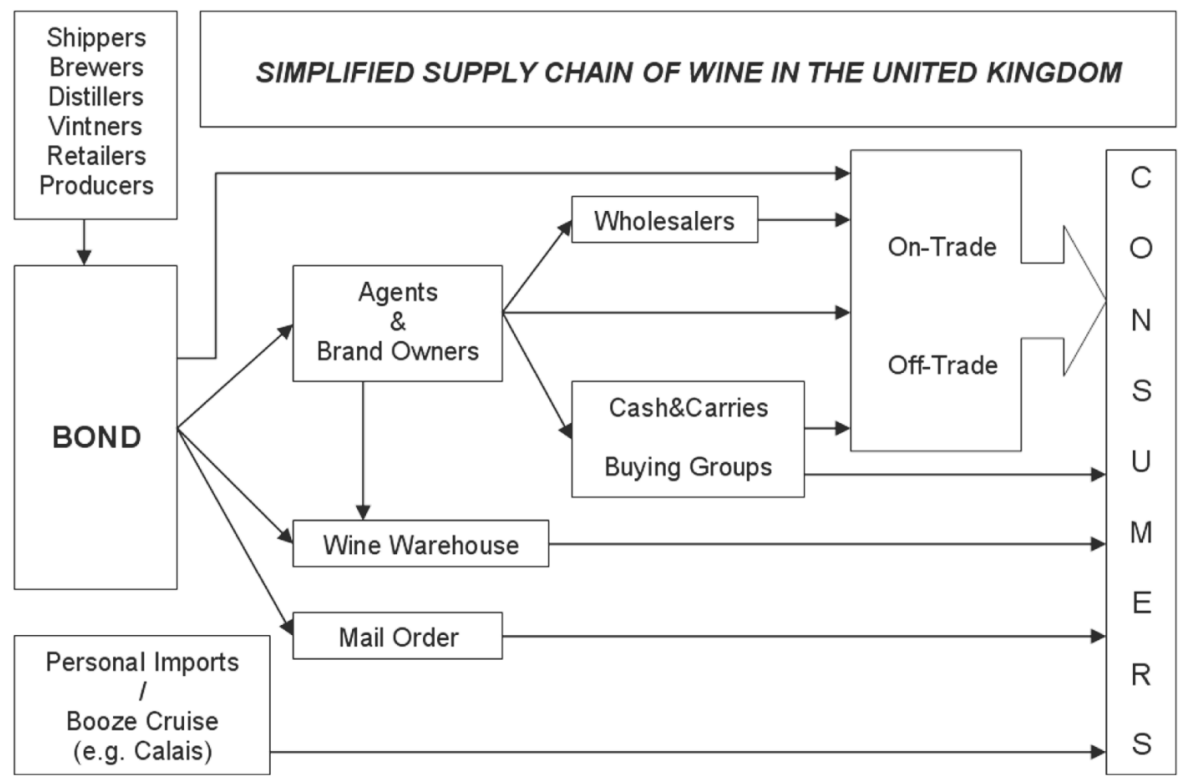

Source: Based on WSTA (2006)
Trends in the British wine market

555
Figure 1. Simplified supply chain of wine in the United Kingdom 
$\mathrm{BFJ}$

110,6

\section{6}

(2) Mail order. Since the internet is becoming familiar to everyone, this purchasing method is becoming increasingly important. Customers seem to appreciate the opportunity to buy wine directly from their computers. Several supermarkets and specialist off-licence groups now offer wine for sale online, including Tesco, Asda, Sainsbury's, Waitrose, Majestic and Oddbins. Of these, Tesco, Waitrose and Majestic have the best-developed web sites and the biggest ranges online.

On-line sales will grow a lot in years to come.

A national brand manager said that:

Supermarkets control the wine market, while independents have lots of difficulties. It seems to me that supermarkets will expand towards new ways of selling wine, like convenience stores [...] Online sales, however, are growing a lot and seem to be very profitable. It is not by chance that almost every supermarket chain sells wine through the internet.

(3) Wine clubs are the main channel for mail order wine sales, distributing regular brochures and leaflets from which customers can order by post or phone. Some wine clubs operate subscription services, sending out a set number of wine cases a year for an annual fee. This sort of wine retailer tends to appeal to upmarket wine connoisseurs seeking services and wine ranges akin to those at an independent wine merchant. Virgin Wines customers, in contrast, tend to be younger and looking to avoid the attention of a wine merchant, feeling intimidated by visiting such a store. An international sales manager stated that:

Wine clubs have their own web site and we know they are very influential on customers. Some of them already sell wine on-line, while some others are planning to start it soon.

The ways in which wine can enter the British market are complex and numerous and affect consumers' consciousness of product attributes.

\section{Conclusions}

This work confirms that, according to the 40 stakeholders interviewed, the four factors of consumer confusion exist in the UK wine market. Many of them are aware of it, but they also confirm that currently consumer confusion reduction strategies are only undertaken by few actors of the supply chain.

Regarding grocery multiple chains, it is arguable that product proliferation trends will continue. Nowadays, NW countries seem to having understood better than OW ones how to approach the British wine market and they currently lead it. Nevertheless there is room for an upward trend for domestic wine consumption as, together with an increase in local production and quality improvement, British consumers will be likely to buy more domestic wines. In order to make it realizable, British wine producers will need to adopt consumer confusion reduction strategies. 
Consumers are exposed to an increasing amount of information. Traditional mass-media channels, word-of-mouth and promotion strategies tend to stress consumer confusion. Among these sources of confusion, every key informant said that they would prefer to eliminate massive promotions, but retailers are too powerful at the moment. Therefore, unless they stop using these incentives, there is no way to break this vicious cycle.

Some strategies have been adopted by suppliers to reduce consumer confusion. For instance, a consideration emerging from the interviews is that if British consumers know the "wine world" better than they did five years ago, Waitrose has certainly contributed to it, cultivating an image of a grocery store for wine lovers. A strategic tool that can be used by supermarkets is the loyalty card. Given that promotion is strategic in the British wine market, as English consumers love a bargain, loyalty cards represent a good way to not over-promoting the wine, because it can then be perceived as a low quality product.

Wine clubs, on one side can increase consumer confusion, on the other side can help consumers to clarify their buying goals mainly if they use tools and adequate information to educate their customers. In this way they can help to instil buyer confidence (Drummond and Rule, 2005).

More work is required to extend this exploratory study on how consumer confusion relates to the British wine market. Particularly, in the light of a valorisation of the emerging UK wine industry, some research about the information provision and the level of consciousness in different consumer segments is necessary, either through qualitative and quantitative researches.

\section{Notes}

1. Drummond and Rule (2005) considered Spawton's marketing mix (the original 4Ps + selling and inventory) as a potential confusion source.

2. Every grocery multiple chain has its own sort of loyalty card. Asda, Sainsbury's, Tesco, Somerfield, M\&S have a "traditional" card. Waitrose and Morrisons, although they do not have a loyalty card, offer to consumers a credit card, which already gives the opportunity to collect points in order to gain vouchers to be spent in chain's shops.

\section{References}

Anderson, K., Norman, D. and Wittwer, G. (2003), "Globalisation of the world's wine markets”, The World Economy, Vol. 26 No. 5, pp. 659-87.

Bradley, P. (1994), “Contract logistics: it's all about costs”, Purchasing, October, pp. 56A3-56A14.

Byrom, J., Parker, C. and Harris, J. (2002), “Towards a healthy high street: identifying skills needs in small independent retailers", Education + Training, Vol. 44 Nos 8/9, pp. 413-20.

Drummond, G. and Rule, G. (2005), "Consumer confusion in the UK wine industry”, Journal of Wine Research, Vol. 16 No. 1, pp. 55-64.

Engineer, R., Phillips, A., Thompson, J. and Nicholls, J. (2003), "Drunk and disorderly: a qualitative study of binge drinking among 18- to 24 year olds", Home Office Research Study 262, Home of Research, Development and Statistics Directorate, London.

Euromonitor International (2006), "Alcoholic drinks in the UK”, available at: www.euromonitor. com

Gold, B.J. (2006), The English Wine Market, Institute of Cape Wine Masters, Cape Town.

\section{Trends in the British wine market}

557 
$\mathrm{BFJ}$

110,6

558
Hackney, R., Grant, K. and Birtwistle, G. (2006), "The UK grocery business: towards a sustainable model for virtual markets", International Journal of Retail \& Distribution Management, Vol. 34 Nos 4/5, pp. 354-68.

Jackson, C.M., Hastings, G., Wheeler, C., Eadie, D. and Mackintosh, A.M. (2000), "Marketing alcohol to young people: implications for industry regulation and research policy", Addiction, Vol. 95 No. 4, pp. S597-S608.

Lincoln, Y.S. and Guba, E.G. (1985), Naturalistic Inquiry, Sage Publications, Thousand Oaks, CA.

Lockshin, L. (2003), "Consumer purchasing behaviour for wine: what we know and where we are going", Cahiers de recherche, Bordeaux Ecole de Management, No. 57-03.

Lockshin, L., Rasmussen, M. and Cleary, F. (2000), "The nature and roles of a wine brand", Australia and New Zealand Wine Industry Journal, Vol. 15 No. 4, pp. 17-24.

Marshall, M.N. (1996), "The key informant technique”, Family Practice, Vol. 13, pp. 92-7.

Mintel International (2005), "Wine retailing - UK", available at: www.mintel.co.uk

Mitchell, V. and Papavassiliou, V. (1999), "Marketing causes and implications of consumer confusion”, Journal of Product and Brand Management, Vol. 8 No. 4, pp. 319-39.

Mitchell, V. and Walsh, G. (2005), "Towards a conceptual model of consumer confusion", Advances in Consumer Research, Vol. 32, pp. 143-50.

New Zealand Wine (2007), “Our role”, available at: www.nzwine.com/role

Prime Minister's Strategy Unit (2004), Alcohol Harm Reduction Strategy for England, Cabinet Office, London.

Read, P.E. (2004), "Developing a grape and wine industry in a non-traditional region", Acta Horticulturae, No. 652, pp. 493-6.

Richardson, O. and Dennis, C. (2003), "Vineyards sector study. Analysis of retail activities using exemplar strategic marketing tools", British Food Journal, Vol. 105 No. 9, pp. 634-52.

Selley, R.C. (2004), The Winelands of Britain: Past, Present, and Perspective, Petravin, Dorkin.

Spawton, T. (1991), "Of wine and live asses: an introduction to the wine economy and state of wine marketing", European Journal of Wine Marketing, Vol. 25 No. 3, pp. 1-48.

Steiner, B. (2004), "French wines on the decline? Econometric evidence from Britain", Journal of Agricultural Economics, Vol. 55 No. 2, pp. 267-88.

Stening, S., Kilov, K., Lockshin, L. and Spawton, T. (2004), “The United Kingdom”, in Anderson, K. (Ed.), The World's Wine Markets: Globalisation at Work, Edward Elgar, Cheltenham, pp. 124-40.

Tremblay, M.A. (1955), “The key informant technique: a nonetnographic application”, American Anthropologist, New Series, Vol. 59 No. 4, pp. 688-701.

Walsh, K. (1999), "Marketing and public sector management”, European Journal of Marketing, Vol. 28 No. 3, pp. 63-71.

WARC (2005), Drink Pocket Book 2006, WARC, Hanley-on-Thames.

Willaims, T.Y. (1967), Field Method in the Study of Culture, Holt, Rindhart and Winston, New York, NY.

WSTA (2006), "Statistics/cross border shopping (between France and Britain)", available at: www.wsta.co.uk

To purchase reprints of this article please e-mail: reprints@emeraldinsight.com Or visit our web site for further details: www.emeraldinsight.com/reprints 